\title{
Aprender a ler brincando: O lúdico como recurso significativo na aprendizagem da
}

\section{leitura}

\author{
Learning to read while playing: The ludic as a significant resource in learning to read \\ Aprender a leer jugando: El juego es un recurso importante para aprender a ler
}

\author{
Recebido: 08/06/2021 | Revisado: 19/06/2021 | Aceito: 24/06/2021 | Publicado: 10/07/2021 \\ Sirlene Lemes de Moraes Silva \\ ORCID: https://orcid.org/0000-0001-9249-4025 \\ Instituto Federal de Educação, Ciência e Tecnologia de Mato Grosso, Brasil \\ E-mail: sula.004@hotmail.com \\ Claudia Lúcia Landgraf Valério \\ ORCID: https://orcid.org/0000-0001-8222-1293 \\ Instituto Federal de Educação, Ciência e Tecnologia de Mato Grosso, Brasil \\ E-mail: claudia.valerio@cba.ifmt.edu.br \\ Edson Gomes Evangelista \\ ORCID: https://orcid.org/0000-0002-2092-533X \\ Instituto Federal de Educação, Ciência e Tecnologia de Mato Grosso, Brasil \\ E-mail:edson.evangelista@blv.ifmt.edu.br
}

\begin{abstract}
Resumo
Provocar nos alunos o gosto pela leitura tem se constituído trabalho dificílimo. Por que é tão difícil fazer com que a leitura se constitua em processo significativo para o estudante do ensino fundamental? Como são trabalhadas as metodologias em sala de aula? Por meio dessas inquietações apresentamos neste artigo a proposta de um trabalho desenvolvido em uma escola estadual em Várzea Grande- MT, no Ensino Fundamental com alunos do $6^{\circ}$ ano e sugestões de alguns jogos e brincadeiras e a importância destes recursos pedagógicos significativos para a aprendizagem da leitura. A escola utiliza-se pouco dos jogos lúdicos na prática de ensino e aprendizagem, e a ausência de métodos eficazes é apontada hoje como a mais importante causa do fracasso do ensino da leitura. Neste sentido, o artigo tem como objetivo apresentar alternativas no processo ensino-aprendizagem e construir estratégias que potencializem o hábito da leitura por meio do lúdico e das brincadeiras para despertar no educando o prazer pela leitura e contribuir para a formação de leitores autônomos e competentes. Realizamos uma pesquisa descritiva e qualitativa e de cunho bibliográfica com os estudos dos autores aqui expostos como Santos (2001), Carvalho (2003), Fortuna (2018), Peixoto \& Venturini (2021), dentre outros. Nessa perspectiva, pretende-se com este trabalho contribuir para o ensino-aprendizagem da leitura por meio do lúdico numa perspectiva construtivista ensinando de forma descontraída e efetiva baseada em teoria e prática. O trabalho apresentou resultados positivos no processo da leitura e escrita dos estudantes.
\end{abstract}

Palavras-chave: Ensino e aprendizagem; Leitura e escrita; Jogos e brincadeiras.

\begin{abstract}
Provoking a taste for reading in students has been a very difficult job. Why is it so difficult to make reading a meaningful process for elementary school students? How are methodologies worked in the classroom? Through these concerns we present in this article a work proposal for developing in a public school in Várzea Grande-MT, in Elementary School with 6th grade students, suggestions for some games and play and the importance of these significant pedagogical resources for learning to read and writing. The school makes little use of playful games in the practice of teaching and learning, and the absence of effective methods is now pointed out as the most important cause of the failure to teach reading. In this sense, the article aims to present alternatives in the teaching-learning process and build strategies that enhance the habit of reading through play and games to awaken the pleasure of reading in students and contribute to the formation of autonomous and competent readers. We carried out a descriptive and qualitative research and bibliographic nature with the studies of the authors exposed here, such as Santos (2001), Carvalho (2003), Fortuna (2018), Peixoto \& Venturini (2021), among others. From this perspective, the aim of this work is to contribute to the teaching-learning of reading through play in a constructivist perspective, teaching in a relaxed and effective way based on theory and practice. The proposal contributed to a positive result in reading and writing process.
\end{abstract}

Keywords: Teaching and learning; Reading and writing; Games and plays.

\section{Resumen}

Provocar el gusto por la lectura en los estudiantes ha sido un trabajo muy difícil. ¿Por qué es tan difícil hacer de la lectura un proceso significativo para los estudiantes de la escuela primaria? ¿Cómo se trabajan las metodologías en el 
aula? A través de estas inquietudes que presentamos en este artículo la propuesta de un trabajo desarrollado en una escuela pública de Várzea Grande- MT, en la escuela primaria con alumnos de $6^{\circ}$ grado, las sugerencias de algunos juegos y bromas y la importancia de estos recursos pedagógicos significativos para el aprendizaje de la lectura y la escritura. La escuela utiliza poco los juegos lúdicos en la práctica de la enseñanza y el aprendizaje, y la ausencia de métodos eficaces se señala hoy en día como la causa más importante del fracaso en la enseñanza de la lectura. En este sentido, el artículo tiene como objetivo presentar alternativas en el proceso de enseñanza-aprendizaje y construir estrategias que potencien el hábito de la lectura a través del juego y los juegos para despertar el placer de leer en los estudiantes y contribuir a la formación de lectores autónomos y competentes. Realizamos una investigación bibliográfica descriptiva y cualitativa con los estudios de los autores aquí expuestos como Santos (2001), Carvalho (2003), Fortuna (2018), Peixoto \& Venturini (2021), entre otros. From this perspective, the aim of this work is to contribute to the teaching-learning of reading through play in a constructivist perspective, teaching in a relaxed and effective way based on theory and practice. La propuesta presentó resultados positivos em el processo de lectura y escritura de los estudiantes.

Palabras clave: Ensenãnza y aprendizaje; Lectura y escritura; Juegos.

\section{Introdução}

Para que os alunos tenham sucesso em sua vida escolar, profissional e social é necessário dominar a leitura e a escrita, pois, são práticas emancipadoras e por meio delas podem participar ativamente da sociedade, bem como o exercício de sua cidadania com consciência e livre arbítrio de suas escolhas.

No decorrer dos anos nas atividades práticas em sala de aula observamos as dificuldades que os alunos têm para ler e escrever, dificuldades estas, que surgem desde o início de sua vida escolar prosseguindo até mesmo no ensino médio. Provocar nos alunos o gosto pela leitura tem se constituído trabalho dificílimo. Por que é tão difícil fazer com que a leitura se constitua em processo significativo para o estudante do ensino fundamental? Como são trabalhadas as metodologias em sala de aula? Diante da constatação da falta do hábito e prazer pela leitura, o estudo partiu da inquietude de como despertar esse hábito e prazer da leitura nos alunos, por meio dos estudos feitos sobre o lúdico como metodologias interessantes para essas práticas.

O projeto "Aprender a ler brincando: O lúdico como recurso significativo na aprendizagem da leitura" foi um trabalho desenvolvido em uma escola estadual com alunos do $6^{\circ}$ ano do Ensino Fundamental, com o objetivo de apresentar alternativas no processo ensino-aprendizagem e desenvolver o hábito da leitura por meio do lúdico e das brincadeiras para despertar no educando o prazer pela leitura e contribuir para a formação de leitores autônomos e competentes, pois por meio dos jogos os alunos podem brincar de maneira espontânea, levantar hipóteses, desenvolver a criatividade, melhorar sua aprendizagem e consequentemente sua autoestima.

Para tanto, propomos atividades que envolvam os usos dos jogos linguísticos e brincadeiras no ensino da leitura. Descobrir o gosto pelos diferentes tipos de leitura, contribuindo para o desenvolvimento das habilidades linguísticas: falar, escutar, ler e escrever e estimular a leitura da criança e adolescente por meio dos diversificados tipos de literaturas.

A leitura precisa ser trabalhada de forma criativa e prazerosa, brincando com as palavras para a obtenção de resultados satisfatórios e, no entanto, percebe-se que na escola se utiliza pouco o lúdico na prática de ensino e aprendizagem e a ausência de método eficaz é apontada hoje como a mais importante causa do fracasso do ensino da leitura e, consequentemente, o da escrita.

Ensinar a leitura utilizando os jogos linguísticos (canções, poesias, parlendas, trava-línguas, cruzadinhas, etc.) e as brincadeiras são importantes recursos pedagógicos para a aprendizagem da leitura, uma vez que cabe a escola proporcionar novas metodologias no processo ensino-aprendizagem da leitura e escrita, visando a descoberta, a invenção, a criatividade e a arte de aprender e apreender novos conhecimentos redescobrindo o poder do brincar de forma coletiva e individual.

O lúdico apresenta valores específicos para todas as fases da vida humana, assim na idade infantil e na adolescência a finalidade é essencialmente pedagógica. A criança e mesmo o jovem opõem-se resistência à escola e ao ensino, porque acima 
de tudo ela não é lúdica, não é prazerosa. De acordo com Snyders (1990) ele defende a alegria na escola, vendo-a não só como necessária, mas como possível.

É importante que a escola crie meios atrativos, atividades diferenciadas lúdicas e pedagógicas, para que essas crianças possam desenvolver suas habilidades com prazer inserido num ambiente agradável, alegre e divertido, na qual a leitura possa ser a chave mestra de seu aprendizado. Estudos demonstram que através de atividades lúdicas, o educando explora muito mais a sua criatividade, melhora sua conduta no processo de ensino-aprendizagem e sua autoestima. Neste sentido, Carvalho (2003, p.14) afirma que:

(...) desde muito cedo o jogo na vida da criança é de fundamental importância, pois quando ela brinca, explora e manuseia tudo aquilo que está a sua volta, através de esforços físicos se mentais e sem se sentir coagida pelo adulto, começa a ter sentimentos de liberdade, portanto, real valor e atenção as atividades vivenciadas naquele instante.

$\mathrm{O}$ autor ainda acrescenta que “(...) o ensino absorvido de maneira lúdica, passa a adquirir um aspecto significativo e afetivo no curso do desenvolvimento da inteligência da criança, já que ela se modifica de ato puramente transmissor a ato transformador em ludicidade, denotando-se, portanto, em jogo" (Carvalho, 2003, p.28). Daí a necessidade de se observar e refletir sobre o pensamento de Santos (2001, p.15), que diz: "Para que o jogo possa desempenhar a função educativa é necessário que este seja pensado e planejado dentro de uma proposta pedagógica". Para fundamentar essa prática, cabe ao docente criar situações diferenciadas, ou seja, novas metodologias para despertar nos alunos o prazer pela aprendizagem.

A utilização de recursos lúdicos é importante para a aprendizagem da Língua Portuguesa e, como consequência, para a aprendizagem das demais disciplinas, pois favorece a relação de interdisciplinaridade, isto é, a integração das outras disciplinas, contribuindo para o rendimento do aluno na aprendizagem. Por meio dos jogos, os alunos podem brincar de maneira espontânea, levantar hipóteses, desenvolver a criatividade, melhorar sua aprendizagem e consequentemente sua autoestima. Ensinar e aprender a ler de forma prazerosa, visando o desenvolvimento da aprendizagem do aluno de maneira criativa, tendo como oportunidade de despertar o interesse no aprender como um momento especial, proporcionando o crescimento humano por meio das atividades diferenciadas.

Os jogos e as brincadeiras são de fundamental importância para o desenvolvimento integral da criança e adolescente no ensino fundamental, como recursos essenciais para a aprendizagem da Língua Portuguesa e como consequência a aprendizagem das demais disciplinas, pois essa metodologia no processo ensino-aprendizagem favorece a relação de interdisciplinaridade, ou seja, a integração das outras disciplinas contribuindo para o rendimento do aluno na aprendizagem.

Todo indivíduo deve vivenciar o brincar utilizando-se de seu livre arbítrio, da vontade e do desejo próprio, assim como também pelo prazer de jogar, ou de encontrar e reencontrar os amigos: estes são elementos que serão norteadores da ação lúdica no brincar. Como coloca Borja (2005) “[...] A partir do jogo livre, você pode desenvolver algum conhecimento e experiência necessárias para a cidadania sustentável". Para isso, nada melhor do que aprender através dos jogos, das brincadeiras e dos brinquedos.

Desenvolver a aprendizagem da leitura brincando com as palavras de maneira prazerosa, é uma prática desafiadora para nós educando, porém como afirma Snyders (1996) "O professor não deve abster de estudar, o prazer pelo estudo e a leitura deve ser evidente, senão não irá conseguir passar esse gosto para seus alunos. O professor que não aprende com prazer não ensinará com prazer”. (Snyders, 1996, p.21). São grandes os desafios que o profissional docente enfrenta, mas manter-se atualizado e desenvolver práticas pedagógicas eficientes são os principais. 


\subsection{O papel dos jogos e brincadeiras na aprendizagem da leitura}

Pode não existir fórmula mágica para o ensino da leitura, mas há caminhos divertidos que conduzem à construção do sentido de um texto. Um deles é o uso dos jogos. Se os jogos e as atividades lúdicas são importantes para a aprendizagem do sistema oral e escrito, porque não fazem parte do cotidiano escolar?

Diversas pesquisas já foram feitas com o objetivo de aprofundar os estudos dos jogos e das brincadeiras como recursos para a aprendizagem da leitura. Por meio delas, percebe-se que, embora nas escolas de educação infantil e fundamental, as crianças sejam expostas a um rico universo linguístico, tais como canções, versos, trava-línguas, poesias, contos etc., observa-se que, na maioria das vezes, a escola trabalha a leitura apenas como decodificação das palavras isoladamente, sendo que existem diversas possibilidades de se ensinar a ler.

Estudos demonstram que através de atividades lúdicas, o educando explora muito mais a sua criatividade, melhora sua conduta no processo de ensino-aprendizagem e sua autoestima. O jogo ao ocorrer em situações sem pressão, em atmosfera de familiaridade, segurança emocional e ausência de tensão ou perigo, proporciona condições para aprendizagem das normas sociais em situação de menor risco. "O jogar é uma atividade recreativa que favorece o comportamento do estudante em ser espontâneo. Enquanto ele brinca, demonstra características do seu perfil, modos de agir e pensar de forma natural." (Peixoto \& Venturini, 2021, p. 4)

A conduta lúdica oferece oportunidade para experimentar comportamento que, em situações normais, jamais seriam tentados pelo medo do erro ou punição. Sendo assim, “o indivíduo criativo é um elemento importante para o funcionamento efetivo da sociedade, pois é ele quem faz descobertas, inventa e promove mudanças". (Kishimoto, 1998, p. 140).

O jogo deve ser utilizado em sala de aula não apenas como entretenimento, mas como prática de aprendizagem para desenvolver a leitura proficiente, transformando-o em recursos para muitas atividades. Segundo as autoras Peixoto e Venturini (2021) "O jogo é uma prática pedagógica interdisciplinar quando utilizado como recurso lúdico e facilitador, possibilitando a interação de duas ou mais áreas de conhecimento.” (p.5)

Acredita-se que, desta forma, podemos preparar jovens conscientes e capazes de enfrentar dificuldades do cotidiano e, com coerência e conhecimento, transformar barreiras e dificuldades em um aliado para a sua prática diária.

Em outros termos, justifica-se então tal prática pedagógica, pois, de um lado, o jogo tem como objetivo o prazer da competição em si (jogo pelo jogo) e, por outro lado, estimula o desejo de ser bem sucedido. A brincadeira oportuniza a descontração, que colabora para o estabelecimento de um bom vínculo entre professor-aluno e aluno-aluno.

Logo, no entendimento de Piaget (1978), constatamos a importância conferida ao jogo infantil. Jogando a criança apreende o mundo e se expressa, recriando-o segundo o seu nível de desenvolvimento, a criança aprende brincando. “(...) o jogo constitui o pólo extremo da assimilação do real ao eu". (Piaget, 1978, p.207).

É através do jogo que a criança aprende a agir, sua curiosidade é estimulada, adquire iniciativa e autoconfiança, proporciona o desenvolvimento da linguagem, do pensamento e da concentração.

Sendo assim, pode-se perfeitamente usar um jogo de linguagem com o objetivo de desenvolver a área intelectual. A diferença vai aparecer na maneira de aplicação do jogo onde a informação, a atenção, o raciocínio etc., serão mais importantes que, por exemplo, o uso correto na forma de pronunciar os vocábulos. Segundo Maria da Glória Lopes (2000, p.25):

A criança aprende brincando, é o exercício que a faz desenvolver suas potencialidades. É pelos jogos e exercícios que se pode trabalhar as habilidades psicomotoras ao mesmo tempo em que se amplia a capacidade de percepção da criança através de experiências emocionais, sociais e intelectuais. 
Piaget (1976) fala que a atividade lúdica é a raiz obrigatória das atividades intelectuais da criança. Estas não são simplesmente uma forma de alivio ou divertimento para gastar energia das crianças, mas meios que colaboram e enriquecem o desenvolvimento intelectual. Ele afirma que

O jogo é, portanto, sob as suas duas formas essenciais de exercício sensório-motor e de simbolismo, uma assimilação da real à atividade própria, fornecendo a esta seu alimento necessário e transformando o real em função das necessidades múltiplas do eu. Por isso, os métodos ativos de educação das crianças exigem todos que se forneça às crianças um material conveniente, a fim de que, jogando, elas cheguem a assimilar as realidades intelectuais que, sem isso, permanecem exteriores à inteligência infantil (Piaget, 1976, p.160).

Muitas vezes, crianças com forte componente de distúrbios de aprendizagem não conseguem se concentrar em determinadas tarefas. Para Fortuna (2018), trabalhar o jogo contribui para um ensino com uma perspectiva mais lúdica, ampliando o processo de ensinar e aprender os conteúdos no cotidiano escolar.

No entanto, por meio dos jogos, a criança passa a ser mais ativa e atenciosa, começa a desenvolver o raciocínio lógico, criando suas próprias hipóteses, aplicando-as e avaliando os resultados obtidos, além de adquirirem a autoconfiança.

Vários jogos são utilizados como instrumento no processo da aprendizagem, dependendo da faixa etária, da maturação e do interesse da criança. São eles: Jogos motores (correr, saltar), jogos intelectuais (damas, xadrez, etc.), jogos competitivos e jogos de cooperação.

O jogo dramático se diferencia dos outros jogos porque envolve representação dramática, envolve personagens e sentimentos. Jogar significa alegria, divertimento, entusiasmo, confiança, aprendizagens e desenvolvimentos ${ }^{1}$.

Também, pode-se trabalhar com a poesia, mostrando seus constituintes verbais, por meio de jogos de ritmos e sonoridade quanto com os significados. Os trava-línguas, cantigas, jogos cantados, parlendas, versos, também são ocasiões para se trabalhar as unidades distintivas da língua, ou seja, levar a criança a localizar as sílabas constitutivas de um enunciado, despertando nela a atenção às unidades sonoras da linguagem, ou seja, aos fonemas.

\section{Metodologia}

Para a realização do projeto, no primeiro momento foi feita uma revisão da literatura com a finalidade de ampliar conhecimentos sobre o tema, centradas nas contribuições teóricas de vários autores como Piaget (1976;1978), Kishimoto (1998), Snyders (1990), Carvalho (2003) e outros para aprofundar mais sobre o assunto, por meio dos jogos e brincadeiras didático-pedagógicas. Após esse estudo teórico, partimos ao campo para a coleta de dados.

Gil (2002), ao tratar da pesquisa de campo como técnica de pesquisa, apresenta alguns instrumentos que normalmente são utilizados nesse tipo de pesquisa. Para o autor, a pesquisa pode ser desenvolvida por meio de aplicação de entrevistas e observação, tendo o questionário como complementar aos instrumentos qualitativos.

Dado exposto foi realizada uma pesquisa descritiva, com abordagem qualitativa, tendo como método estudo de caso. Segundo Lakatos e Marconi (2003, p. 108), estudo de caso "consiste no estudo de determinados indivíduos, profissões, condições, instituições, grupos ou comunidades [...] observando todos os fatores que o influenciaram e analisando-o em todos os seus aspectos". Gil (2002, p. 141), ainda assevera que "o método do estudo de caso pode ser considerado o mais completo dentre todos os outros, pois, este se vale tanto de dados de pessoas quanto de dados documentais. [...]". Segundo Vieira e Zouain (2005), a pesquisa qualitativa atribui importância fundamental aos depoimentos dos atores sociais envolvidos, aos

\footnotetext{
1 Tezani, T.C.R. O jogo e os
} http://www.profala.com/artpsico38.htm. 
discursos e aos significados transmitidos por eles. Nesse sentido, esse tipo de pesquisa preza pela descrição detalhada dos fenômenos e dos elementos que o envolvem.

A coleta de dados foi feita por meio de entrevistas, questionários, observações e práticas das atividades desenvolvidas com as crianças em sala de aula, com o objetivo de buscar maiores informações sobre as dificuldades existentes possibilitando um aprendizado consistente da leitura voltada para o crescimento integral do ser humano, podendo ser trabalhada de forma satisfatória, baseado nos conhecimentos teóricos sobre o assunto com a finalidade de formular problemas e hipóteses, desafiando as crianças a solucionarem problemas, estabelecendo relações a fim de construírem uma aprendizagem real.

Segundo Gil (2002, p.128), o questionário pode ser definido "como a técnica de investigação composta por um número mais ou menos elevado de questões apresentadas por escrito às pessoas.”. Assim, o questionário foi uma das técnicas que serviu para coletar as informações da realidade para se chegar ao resultado da pesquisa abordada.

A caracterização dos sujeitos da pesquisa se compôs na delimitação de alunos do $6^{\circ}$ ano do ensino fundamental da Escola Estadual "Dunga Rodrigues”, situada na Av. Julião de Brito S/N, Bairro: Maringá III - Várzea Grande/ MT.

Nessa perspectiva, pretendeu-se com este trabalho utilizar esses recursos numa perspectiva construtivista ensinando de forma descontraída e efetiva a aprendizagem da leitura baseada em teoria e prática não somente no ensino da Língua Portuguesa, mas em qualquer área do conhecimento de forma sistematizada e contínua.

Entendemos que desenvolver o gosto pela leitura, é um processo lento e deve ser trabalhado interativamente com as demais disciplinas curriculares como também a colaboração familiar e da direção da escola, centrado em um apoio cultural e político vinculado com diversos ambientes interativos contribuindo assim, para a transformação da informação em grandes descobertas e conhecimentos e estimulando infinitamente seres pensantes.

\subsection{Prática da leitura e ludicidade}

Ler não é apenas decodificar códigos, ler é atribuir significado, sentido ao que está lendo. A leitura precisa ser uma rotina diária na vida de todos, pois é a partir do diálogo com os textos é que desenvolvemos o senso crítico, compreensão e reflexão daquilo que lemos. Zilberman enfatiza que a leitura hoje nas escolas está em crise e atribui isso à maneira de como a escola tem influenciado a leitura na vida diária dos educandos. A autora destaca ainda que a leitura nas salas de aulas realiza-se de forma descontextualizada sendo trabalhadas somente com os livros didáticos sem nenhum atrativo. "A escola deve ter a preocupação cada vez maior com a formação de leitores, ou seja, estimular leitores críticos, com saberes que ultrapassem a sala de aula, para que saibam lidar com suas especificidades" (Delmanto 2009).

A escola deve cumprir com o seu papel no processo de aprendizagem de leitura do aluno, que é fundamental na sua vida escolar e social, de modo a motivá-lo para a prática de leitura e escrita e oferecer trabalho com projeto de leitura para desenvolver o gosto motivado pelo prazer interligando-o à sua vida cotidiana. Os professores têm, então, papel de mediadores do conhecimento. Segundo Martins (1984, p.34):

A função do educador não seria precisamente ensinar e ler, mas a de criar condições para o educando realizar sua própria aprendizagem, conforme seus próprios interesses, necessidades, fantasias, segundo as dúvidas e exigências que a realidade lhe apresenta.

Além de a escola tomar posto da função de subsidiar no ensino da leitura e da escrita, conferindo aos professores o trabalho de chamar a atenção dos alunos para a leitura e a desenvolver a escrita de forma a expressar ideias e pensamentos, cabe à sociedade influenciar tais práticas de forma a colaborar com o desenvolvimento do aluno como leitor dentro e fora da escola. Sendo amparado pela escola e sociedade, o aluno terá informações efetivas para que seu desenvolvimento como leitor seja de qualidade. 
Segundo Simões (2012, p. 14) "se queremos formar cidadãos críticos, temos que acolher, praticar e desenvolver a participação criativa, crítica e atuante nas nossas próprias salas de aula como espaços de ação social democrática". No entanto, é preciso oferecer aos estudantes um ponto de partida para a promoção do hábito e prazer da leitura e nada melhor que trabalhar como assevera Cardoso e Jung (2018), no ambiente educacional, o lúdico propicia as crianças desenvolverem suas habilidades, socializarem além de contribuir para que superem seus medos e dificuldades medos.

Nessa perspectiva, serão apresentadas algumas propostas metodológicas, como jogos e brincadeiras usados como recursos para o trabalho com a prática da leitura para alunos do $6^{\circ}$ ano do Ensino Fundamental. Vale ressaltar que essas propostas foram compiladas de vários estudos cujo interesse é facilitar o aprendizado da leitura por meio do lúdico. Sendo assim, alerta-se para o fato de que as sugestões abaixo relacionadas não são originais, sendo aqui reunidas com o propósito de mostrar ao professor as várias possibilidades de inserir o lúdico no processo de ensino/aprendizagem da leitura.

\section{Dramatizações}

As dramatizações são ações espontâneas nas quais os alunos elaboraram textos verdadeiros, pois os diálogos surgem facilmente, sendo todos ao mesmo tempo coautores e protagonistas. As atividades como cantar, entender a música, conhecer instrumentos são formas de cultivar a sensibilidade e criatividade natural das crianças. Esse jogo em como objetivo: fazer com que o aluno perceba características do gênero dramático interprete o texto teatral e consiga perceber a relação entre fantasia e realidade.

O professor necessita esclarecer a diferença entre a encenação e o texto escrito de uma peça, enfatizando suas particularidades para a representação, diferente do texto narrativo. Este tem um narrador que faz a mediação com o leitor, ao contrário o que acontece no texto teatral, onde, os fatos acontecem diante do próprio espectador.

De acordo com Castanho (1990, p.313) "o jogo dramático, portanto, difere de outros jogos por acontecer no contexto dramático e, além disso, por envolver os participantes emocionalmente na atividade de expressar as criações de seu mundo interno".

\section{Jogos linguísticos}

Como jogos linguísticos, incluem-se as poesias, as parlendas, trava-línguas e os jogos de palavras, memorizados e repetidos que, segundo o Referencial Curricular Nacional para a Educação Infantil (1998, v. 3 p. 141), "possibilitam às crianças atentarem não só aos conteúdos, mas também à forma, aos aspectos sonoros da linguagem, como ritmo e rimas, além das questões culturais e afetivas envolvidas". Abaixo segue exemplos de atividades:

\section{- Trava-língua}

Jogos com palavras que, como indica o nome, apresentam reprodução de consoantes e vogais de modo a tornar difícil a leitura. Consiste na prática da oralidade, proferindo todas as letras; à medida que a profere torna-se fácil, aumentar a rapidez da leitura. Essa atividade tem como objetivo, promover uma disputa de trava-línguas entre as equipes e quem se sair melhor, vence a prova.

\section{- Criando poemas}

O jogo de criação de poemas se baseia em um tipo de relação entre as palavras e a sua organização na folha de papel. O aluno não arrumará as palavras de um modo "engraçadinho", mas sem qualquer sentido, podendo usar as rimas, combinando as palavras. Criar poesias é brincar com as palavras na folha de papel.

Essa atividade tem como objetivo: fazer com que os alunos conheçam os modos não convencionais de fazer poesia consigam interpretar poemas concretos e criar poemas combinando palavras. 
Os jogos linguísticos necessitam acompanhar o desenvolvimento da criança seguindo um aumento no nível de complexidade logo que a criança se apresente pronta para isso.

\section{Jogos de palavras}

De acordo com Programa Gestão da Aprendizagem Escolar ${ }^{2}$ - Gestar II Língua Portuguesa: Atividade de Apoio à Aprendizagem 2 AAA2, (2008, p.17), os jogos com palavras compõem uma das maneiras mais prazerosas e curiosas de fazer com que o aluno tenha interesse pela língua. Desta maneira cabe ao professor estimular a percepção do som, da estrutura e da grafia das palavras e a variação das combinações de letras e sílabas. ${ }^{3}$

Ao brincar com as palavras da nossa língua os alunos apresentam o domínio de brincar com a sonoridade, constituição e o sentido das palavras. Se entender interessante, o professor poderá organizar grupos de alunos e determinar tempo para que resolvam cada exercício ${ }^{4}$, ajudando-os em suas dificuldades e fornecendo sugestões para cada exercício.

A brincadeira resulta em ler as palavras da direita para a esquerda ou da esquerda para a direita e sempre tem um sentido, e tem como objetivo: fazer com que os alunos percebam o caráter lúdico da língua reflitam sobre aspectos fonéticos, morfológicos e semânticos da língua para entender alguns de seus mecanismos e desenvolvam a fluência por meio de leitura de trava-línguas.

\section{Jogo da memória}

O jogo de Memória consiste em que um aluno comece dizendo uma frase, e os demais repitam e aumentem, até que chegue no último aluno. $\mathrm{O}$ aluno vencedor será aquele que conseguir repetir a frase toda sem tropeçar e/ou trocar palavras pronunciando-as como no início.

\section{Dicionário}

O manual de Educação Física e Recreação (p.28), explica que, no jogo do dicionário várias equipes jogam no mesmo instante onde cada equipe recebe 3 placas (A, B e C), e em cada jogada, o líder escreve no quadro uma palavra que nenhuma pessoa conhece e apresentará três definições: uma correta e duas erradas. E quando der as orientações, todas as equipes devem levantar suas placas ao mesmo momento, sendo que as equipes com mais acertos ganham a partida.

\section{Bingo com classes gramaticais}

Segundo professora Renata Ramalho, o jogo do Bingo possibilita o trabalho com as classes gramaticais, sendo sugerida a atividade a seguir:

É necessário preparar as cartelas, no estilo convencional das de bingo, divididas em quadrinhos (sugere-se $4 \times 4$ ou 16 casas), logo após, deve-se escrever o nome das classes gramaticais em onze espaços, deixando cinco espaços vazios.

Os espaços vazios são muito importantes, pois permitem uma visualização mais clara e reduzem o tempo da atividade. As cartelas devem ser diferentes entre si, podendo haver, é claro, algumas classes repetidas.

O professor deve confeccionar as fichas com palavras que correspondem às classes gramaticais estudadas, elas devem corresponder às pedrinhas numeradas do bingo tradicional.

\footnotetext{
${ }^{2}$ Programa Gestão da Aprendizagem Escolar - Gestar II. Língua Portuguesa: Atividade de Apoio à Aprendizagem 2. AAA2: análise linguística e análise literária (versão do professor). Brasília: Ministério da Educação; Secretaria da Educação Básica, 2008 , p. 17.

${ }^{3}$ Programa Gestão da Aprendizagem Escolar - Gestar II. Língua Portuguesa: Atividade de Apoio à Aprendizagem 2. AAA2: análise linguística e análise literária (versão do professor). Brasília: Ministério da Educação; Secretaria da Educação Básica, 2008, p. 17

${ }^{4}$ Idem.
} 
O aluno que tiver em sua cartela a classe gramatical da palavra que foi dita, deverá escrevê-la na casa correspondente. $\mathrm{O}$ aluno que conseguir completar primeiro todos os itens da sua cartela será o vencedor.

\section{Gincana-Soletrando}

O Soletrando consiste em soletrar as palavras corretamente e, caso o participante tropeçar na letra, é eliminado, caso acerte, continua a participar do jogo. O vencedor é aquele que soletrar mais números de palavras corretamente.

\section{Ordenando as partes}

No livro do Programa Gestão da Aprendizagem Escolar - Gestar II Caderno de Teoria e Prática 5 - TP5 (2008, p. 95), nos sugere que através da coordenação das partes de um texto verbal narrativo, é possível trabalhar com critérios de atribuição e coerência, ainda que nem sempre os fatos são narrados obedecendo à ordem cronológica de sua ocorrência. Mesmo assim, existem palavras próprias que resgatam a sequência dos fatos.

O jogo Ordenando as Partes consiste em dividir a classe em grupos, onde o professor tem que ter um texto fotocopiado para cada grupo, posteriormente, dividir o texto em várias partes e entrega-las para cada grupo com as partes desordenadas. Cada grupo irá organizar os textos de diferentes maneiras, mantendo a continuidade de sentido e, consequentemente, a coerência do texto.

\section{História maluca}

No livro do Programa Gestão da Aprendizagem Escolar - Gestar II: AAA6 5 (2008, p. 65), nos sugere a construção de um texto narrativo coletivo "Uma história maluca", a partir de alguns recortes imagens de revistas e jornais. Escolher um colega para formar uma dupla. A seguir, folhear a revista ou jornal e selecionar 10 imagens para recortar. Escolher um dos recortes para participar da produção. Cada dupla de aluno poderá participar com uma imagem. Para que a sua imagem faça parte da história, a dupla deverá encaixar a imagem na história, mas sem perder o sentido do que está sendo contado. Fique atento às dicas que o professor irá oferecer durante a brincadeira e auxilie o colega em dificuldade quando souber a melhor maneira de encaixar uma imagem (ideia) no texto iniciado. Atenção para a organização do texto coletivo. A história necessita ter começo, meio e fim, ordenados a partir da sequência dos acontecimentos. O professor inicia a história e cada dupla deverá tentar encaixar a sua figura (ideia) dando sequência na produção. Colabore com a história, não apenas inserindo a sua figura, mas analisando a melhor ordem dos fatos, a relação de causa e consequência e, principalmente, à construção de sentido no texto. Registre o texto produzido pela turma $\mathrm{m}$ seu caderno e reserve as imagens que restaram para outras atividades sugeridas pelo professor.

\section{Resultados e Discussão}

Na prática cotidiana em sala de aula, constatamos dificuldades que muitos alunos apresentam têm para ler e escrever e que se perdura no decorrer dos anos, não demonstrando interesse nenhum pela leitura. Percebemos que muitas vezes essa indiferença é causada pela maneira como são trabalhadas as metodologias em sala de aula desmotivando-os no prazer pela leitura. Diante dessas reflexões e pela constatação da falta do hábito e prazer pela leitura trazendo como consequências dificuldades na escrita, surgiu o interesse de pôr em questão o estímulo pela leitura e escrita por meio dos estudos feitos sobre o lúdico como metodologias interessantes para essas práticas.

\footnotetext{
5 Programa Gestão da Aprendizagem Escolar - Gestar II. Língua Portuguesa: Atividades de Apoio à Aprendizagem 6 - AAA6: Leitura e processos de escrita II. (Versão do Professor). Brasília: Ministério da Educação, Secretaria de Educação Básica, 2008.132 p.: iI
} 
O desenvolvimento das atividades práticas deu-se durante as aulas observando as dificuldades encontradas nas atividades propostas, adaptando as dificuldades para um trabalho no concreto, por meio de jogos linguísticos como: leitura de poema, declamações de poesias, competições de trava-línguas, parlendas, contação de histórias com fantoches confeccionados pelos próprios alunos, dramatização, corrida do dicionário, bingo ortográfico, bingo das classes gramaticais, ditado maluco, ordenando as partes de um texto, cruzadinhas, forca, soletrando, caça-palavras, o que é, o que é? Dentre outras atividades fascinantes desenvolvidas com trabalho em equipe, colaborativo, visando uma aprendizagem significativa.

Durante as aulas, os alunos mostravam-se alegres e eufóricos por estarem fazendo parte do processo de construção dos materiais e por meio destes conhecerem um pouco sobre as metodologias que seriam trabalhadas no decorrer das aulas, possibilitando aos estudantes um aprendizado efetivo, criativo e significativo por meio dos jogos e brincadeira. A partir da experiência que os alunos vivenciaram com os recursos diferenciados e confeccionados por eles, obtivemos resultados satisfatórios em suas atividades como leitura, oralidade, produção textual, formulação e resolução de problemas.

\section{Considerações Finais}

Neste artigo, buscou-se contribuir para aprendizagem da leitura por meio da prática de alguns jogos e brincadeiras em sala de aula, prezando pela importância de inserir o lúdico como proposta alternativa para o ensino/aprendizagem da leitura, em função de se compreender a ludicidade como fator essencial para o desenvolvimento afetivo, cognitivo e intelectual.

Dessa maneira, o objetivo maior do trabalho aqui apresentado, foi mostrar que esse brincar com as palavras, apresenta um papel essencial no desenvolvimento cognitivo das crianças. Mas, será que os educadores estão conscientes da sua importância junto às crianças? Será que há uma preocupação da parte deles em tornar esses jogos linguísticos sistemáticos, organizando sua realização, dando a eles seu devido valor e sem considera-los como mero passa tempo?

É por meio das brincadeiras que a criança entende sobre o que são as regras, porque respeitá-las, o seu relacionamento com os colegas se amplia por meio da interação dela com o outro. A ludicidade facilita a criança expressar-se com mais desenvoltura, ouvir e expor suas ideias concordando ou discordando de outros. É por meio dos jogos e brincadeiras que o estudante exerce sua liberdade e liderança. Na prática da escrita e leitura, é possível perceber que os jogos contribuem para um aprendizado significativo, permitindo que a criança experimente situações, testes hipóteses, amplie sua criatividade e sua relação social, diferentes habilidades e competências.

Diante do exposto e da experiência vivenciada enfatizamos que o professor não deve somente preocupar-se com a quantidade de atividades a serem propostas e nem mesmo os textos devem ser pretextos para um trabalho mecânico e monótono com o ensino das regras gramaticas, como enfatiza Lajolo (1982) em uma reflexão para o ensino da leitura, e sim inquietar-se por aulas com qualidade para alcançar os corações dos educandos.

Cabe ressaltar que não é um trabalho fácil, mas significativo quando temos êxito no que fazemos e quando fazemos por amor, direcionando nossos educandos a se tornarem protagonistas de seus próprios conhecimentos, despertando-os para o hábito da leitura e consequentemente na formação de leitores ativos, críticos e reflexivos. Esses recursos não são apenas formas de divertimento, são meios significativos de aprender e apreender novos conhecimentos proporcionando aos alunos em todos os níveis de escolarização, o prazer de fazer novas descobertas, de forma coletiva e individual, criando, inventando, desenvolvendo a sua capacidade de raciocínio bem como a sua expressão oral e escrita.

Cabe ao educador a responsabilidade de uma aprendizagem consistente para o desenvolvimento de pessoas competentes, com a mente em constante exercício, e para isso, metodologias diferenciadas devem estar presentes no cotidiano da sala de aula, provocando estímulos aos alunos na busca pelo saber. Acredita-se que relacionar o lúdico como 
potencializador da aprendizagem da leitura e escrita em sala de aula, por meio da descoberta e invenção seja fator fundamental para o desenvolvimento integral da criança e do adolescente no contexto escolar.

\section{Referências}

Borja, M. S. (2005). Las ludotecas: instituiciones de juegos. Colección Recursos, n²9. Octaedro.

Brasil. (1998). Ministério da Educação e do Desporto. Secretaria de Educação Fundamental. Referencial Curricular Nacional para a Educação Infantil/ Ministério da Educação e do Desporto. Secretária de Educação Fundamental. MEC/SEF, 3v.:II.

Cardoso, J. I. W., \& Jung, H. S. (2018). O lúdico na educação infantil: aprendizagem e diversão. In: Semana Científica da Unilasalle (SEFIC), Canoas. Anais do SEFIC 2018. https://anais.unilasalle.edu.br/index.php/sefic2018/article/view/1064/1007.

Carvalho, A. M. C. et al. (Org.), (2003). Brincadeira e cultura: viajando pelo Brasil que brinca. (2a ed.), Casa do Psicólogo.

Castanho, G..P. (1990). O jogo dramático na formação do Psicodramatista. Ania VII Congresso Brasileiro de Psicodrama.

Delmanto, D. (2009). A leitura em sala de aula. Construir Notícias, 45, $24-26$

Fortuna, T. R. (2018). Ludicidade. Educar é brincar. Brincar é aprender. :〈www.ufrgs.br/faced/extensao/brincar >

Gil, A. C. (2002). Como elaborar projetos de pesquisas. (7a ed.), Atlas, 2002.

Kishimoto. T. M. (org.) (1998). O brincar e suas teorias. Pioneira.

Lajolo, M. (1982). O texto não é pretexto, in Leitura em Crise na Escola. As Alternativas do Professor. Regina Zilberman (org.), mercado Aberto.

Lakatos, E M.\& Marconi, M. A. (2003). Fundamentos de metodologia científica. (3a ed.), Atlas.

Lopes, M.G. (2000). Jogos na Educação: criar, fazer, jogar. (3a ed.), Editora Cortez.

Martins, M. H. (1984). O que é leitura. Brasiliense.

Peixoto, S. C., \& Venturini, A. (2021) Jogos pedagógicos: Um recurso didático para a aprendizagem de Ciências e Matemática na educação inclusiva para o ensino fundamental - anos finais. Research, Society and Development, 10(6). <https://rsdjournal.org/index.php/rsd/article/view/15525/13889>

Piaget, J. (1976). Psicologia e Pedagogia. Trad. Por Dirceu Acciolly Lindoso e Rosa Maria Ribeiro da Silva. Forense Universitária.

Piaget, J. (1978). A formação do símbolo: imitação, jogo e sonho, imagem e representação. (3a ed.), Zahar.

Prodanov, C. C. (2013). Metodologia do trabalho científico: métodos e técnicas da pesquisa e do trabalho acadêmico. (2a ed.), Feevale.

Programa Gestão da Aprendizagem Escolar - Gestar II, (2008). Língua Portuguesa: Atividades de Apoio à Aprendizagem 2. AAA2: Análise linguística e análise literária (Versão do Professor). Brasília: Ministério da Educação. Secretaria de Educação Básica.

Programa Gestão da Aprendizagem Escolar - Gestar II, (2008). Língua Portuguesa: Atividades de Apoio à Aprendizagem 6. AAA6: Leitura e Processos de escrita II (Versão do Professor). Brasília: Ministério da Educação. Secretaria de Educação Básica. 132 p.; il

Santos, S.M. P. (org.), (2001). A Ludicidade como ciências. Vozes, p. 15.

Simoes, L.J. (2012). Leitura e autoria: planejamento em Língua Portuguesa e Literatura; colaboração de Ana Mariza Filipoouski, Diana Marchi e Joice Welter Ramos; ilustrações de Eloar Guazelli. - Erechim: Edelbra.

Snyders, G. (1990). Entrevista dada à Lourdes Stamato de Camilles, PUC/SP.

Snyders, G. (1996). Alunos felizes. Paz e Terra.

Vieira, M. M. F. e Zouain, D. M. (2005). Pesquisa qualitativa em administração: teoria e prática. Editora FGV.

Zilberman, R. (1986). Leitura em crise na escola: as alternativas do professor. (7a ed.), Mercado Aberto. 